\title{
Éducation, environnement et cultures autochtones
}

Colloque du vendredi 5 mai 2006 - Montréal, Québec

\section{Lucie Sauvé}

\section{CpenEdition}

\section{Journals}

Édition électronique

URL : http://journals.openedition.org/ere/4110

DOI : $10.4000 /$ ere. 4110

ISSN : 2561-2271

Éditeur

Centr'ERE

Référence électronique

Lucie Sauvé, "Éducation, environnement et cultures autochtones », Éducation relative à l'environnement [En ligne], Volume 6 | 2007, mis en ligne le 14 septembre 2007, consulté le 24 septembre 2020. URL: http://journals.openedition.org/ere/4110 ; DOI : https://doi.org/10.4000/ere.4110 


\section{Éducation, environnement et cultures autochtones}

Colloque du vendredi 5 mai 2006 - Montréal, Québec

\section{Lucie Sauvé}

\section{Ectucation, environnement \\ et cultures autochtones}

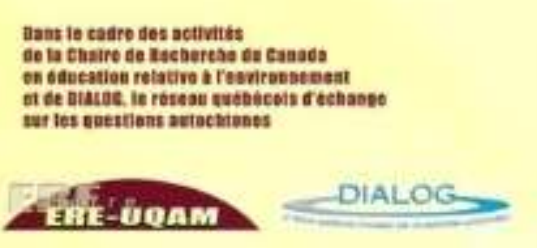

1 Ce colloque a été organisé dans le cadre des activités de la Chaire de recherche du Canada en éducation relative à l'environnement (UQAM) et de DIALOG, le Réseau québécois d'échange sur les questions autochtones (Institut national de la recherche scientifique, Centre Urbanisation, Culture et Société). Il a réuni des acteurs de l'éducation autochtone et de l'éducation relative à l'environnement en contexte autochtone. Il a permis de mettre en dialogue les fondements et les pratiques de l'éducation autochtone et ceux de l'éducation relative à l'environnement.

2 Une double hypothèse a orienté les échanges lors de ce colloque : d'une part, il apparaît que la vision du monde que renforce l'éducation autochtone peut enrichir le domaine de l'éducation relative à l'environnement ; d'autre part, certains courants d'intervention en éducation relative à l'environnement pourraient permettre un déploiement novateur des pratiques éducatives qui émanent de la modernité autochtone et des dynamiques sociales et politiques dans lesquelles s'inscrivent leurs 
projets d'affirmation et de développement. Le dialogue suscité par ce colloque a requis un exercice de redéfinition et de repositionnement des idées mêmes d'éducation, d'environnement et de nature selon les cultures de référence. Il a également invité les participants à considérer les univers de l'éducation autochtone et de l'éducation relative à l'environnement comme des champs de pratique sociale, dont le paysage est complexe, pluriel et évolutif.

Les objectifs de ce colloque ont été formulés comme suit :

- Caractériser le rapport à l'environnement et à la nature selon des expériences éducatives diversifiées en milieu autochtone.

- Identifier des zones de convergence entre ces expériences éducatives et certaines propositions d'éducation relative à l'environnement.

- Cerner leurs apports mutuels.

- Explorer les enjeux liés à la construction d'une interface novatrice entre éducation autochtone et éducation relative à l'environnement.

4 Un CD-Rom a été produit de façon à garder une trace des communications et des échanges, entre les participants autochtones et non-autochtones, axés sur les défis de l'interculturalité. Ce dernier peut être obtenu en s'adressant à la Chaire de recherche du Canada en éducation relative à l'environnement (ere@uqam.ca)

\section{AUTEUR}

\section{LUCIE SAUVÉ}

Chaire de recherche du Canada en éducation relative à l'environnement, Université du Québec à Montréal 